\title{
Performed Notification
}

National Cancer Institute

\section{Source}

National Cancer Institute. Performed Notification. NCI Thesaurus. Code C93412.

The completed activity within the context of a given study that represents the communication of a message to a recipient. 